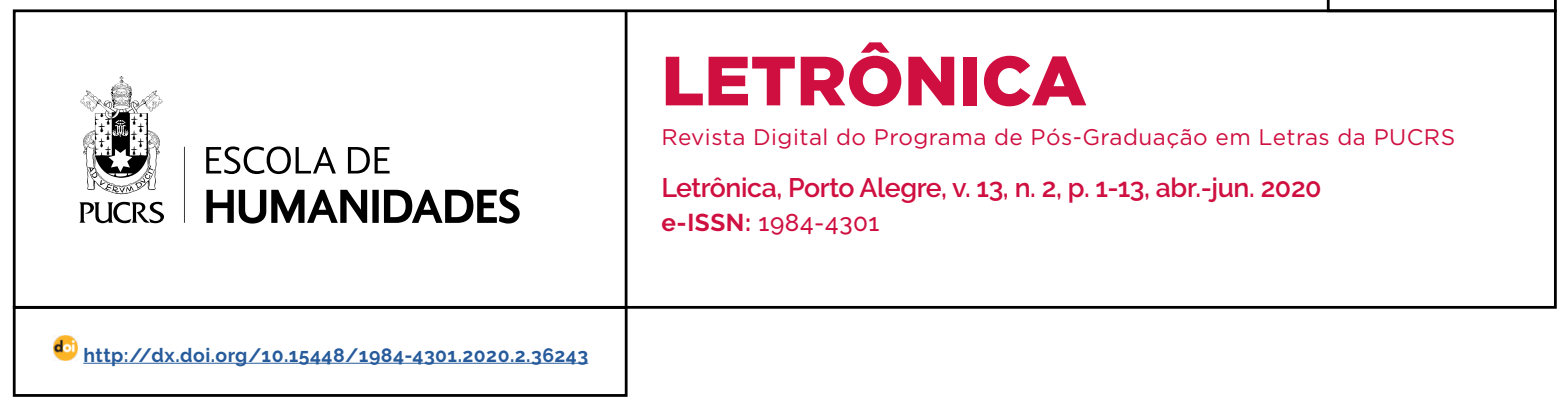

\title{
A violência da palavra em ausência no processo discursivo de representação das mulheres: uma análise do Projeto de Lei $\mathbf{n}$. 01-00352/2019
}

The violence of the word in absence in the discursive process of women's representation: an analysis of Bill n. 01-00352/2019

Fábio Luiz de Castro

Dias $^{1}$

orcid.org/0000-0002-6755-1048

castrodias.f.l@gmail.com

\section{Marina Alvarenga}

Botelho

orcid.org/0000-0002-4351-2415

inabotelho@gmail.com

\section{Marco Antonio Villarta-}

Neder ${ }^{1}$

orcid.org/0000-0003-3857-3720

villarta.marco@ufla.br

Recebido em: 6 nov. 2019. Aprovado em: 22 mar. 2020 Publicado em: 13 ago. 2020.

\section{(c) (1)}

Artigo está licenciado sob forma de uma licença Creative Commons Atribuição 4.0 Internacional.
Resumo: A partir do campo epistemológico do Círculo de Bakhtin, Medviédev e Volóchinov - CBMV, doravante -, em diálogo com aspectos da filosofia foucaultiana, almejamos, aqui, estabelecer uma análise dos processos discursivos de representação das mulheres no Projeto de Lei n. 01-00352/2019 da Câmara Municipal de São Paulo, pelo qual se instauram atos simbólicos de violência contra a autonomia e contra o corpo da figura feminina, à qual, consequentemente, não se concede margem para representar-se pela sua própria voz. Para realizá-lo, nos fundaremos, preferencialmente, nos conceitos de palavra em ausência, de enunciado, de arquitetônica, de dialogismo, de gnosiologismo e de monologismo de Mikhail Bakhtin (2010, 2011, 2017, 2019), articulando-nos, quando necessário, no interior dos domínios filosóficos de Michel Foucault $(1999,2002)$ para, assim, compreender certas faces dos fenômenos discursivos.

Palavras-chave: Discurso. Representação. Enunciado. Gnosiologismo. Monologismo.

Abstract: From Bakhtin, Medvedev and Volochinov's Circle (BMVC) epistemological field, in dialogue with aspects of Foucaultian philosophy, we aim here to analyze the discursive processes of women's representation in São Paulo City Council Bill 01-00352/2019, by which symbolic acts of violence are instituted against the autonomy and the body of female figure, to whom, consequently, there is no room for representation by her own voice. In order to do that, we preferentially base ourselves on Mikhail Bakhtin's (2010, 2011, 2017 and 2019) concepts of word in absence, utterance, architectonic, dialogism, gnosiologism and monologism, articulating them, when necessary, with the philosophical domains of Michel Foucault (1999 and 2002), in order to understand certain faces of discursive phenomena.

Keywords: Discourse. Representation. Utterance. Gnosiologism. Monologism.

\section{Introdução}

Os corpos humanos, para além de sua composição extensa, podem se compreender como corporeidades sígnicas em relação às quais e por meio das quais as consciências instauram-se na eventicidade histórica, percebendo-se na e pela alteridade, o que se dá pela relação dos sujeitos, não somente com os lugares pelos quais se movimentam e os quais ocupam no mundo, mas com os lugares (de) outros através dos quais se constituem.

Pelo nosso viés dialógico, parece-nos não haver a possibilidade de concepção de uma consciência do corpo como um mero objeto. Um 
corpo se torna corpo, corporificando-se porque é percebido como corpo na eventicidade histórica na qual se instaura. Ao mesmo tempo, a sua corporeidade constrói-se pela consciência através da qual e em relação à qual se posiciona como uma representação ideológica. Trata-se de uma constituição dialógica por meio da qual se institui a sua abertura ético-existencial à materialidade do mundo enquanto acontecimentos concretos, de sujeitos em alteridade.

Ao corpo, portanto, podemos conferir sentidos distintos e valores inúmeros, a depender da ordem histórica e social na qual nos encontramos. Na mesma direção, parece-nos aceitável que o consideremos, nas sociedades, não somente como um fenômeno natural, isto é, como um organismo material com as suas constituições biológicas e fisiológicas, mas, sim, principalmente, como um fenômeno social, cuja organização se dá através de encarnações ideológicas instauradas nas e pelas manifestações discursivas entre os sujeitos em uma organização histórica e social. Do ponto de vista teórico, axiológico e metodológico que assumimos aqui, o conceito de enunciado consiste em encadeamento de signos que se emergem de um sujeito e se dirigem a um outro (VOLOCHÍNOV, 2019, p. 280). E, assim, entendemos os corpos como signos. Em seu encadeamento dialógico, os seus atos tornam-se os meios pelos quais se corporificam enquanto posicionamentos ideológicos, desde a sua gênese biológica ao seu movimento ontológico. Assim, temos, igualmente, uma dimensão ética dos nossos atos enunciativos de nossas representações enquanto sujeitos com as nossas corporeidades.

Sobre os corpos, tratando-se de representações discursivas, sempre se buscou exercer uma espécie de dominio, seja sobre a sua corporeidade louca, seja sobre a sua corporeidade sexual, como nos revela o filósofo Michel Foucault [1926-1984], respectivamente, em seu História da loucura (1978) e em seu História da sexualidade (1988). Desde 1500, como nos afirma Teles (1993), as mulheres brasileiras sofrem profundas formas de controle de seus corpos, de seus direitos reprodutivos e, consequentemente, de seus discursos. Separava-se a ideia de prazer da ideia de reprodução. Desde "sempre", na nossa história registrada, os homens brancos possuíam a "posse" do corpo e da reprodução da mulher.

Souza (2017, p. 44), mostrando-nos a questão do controle sobre o corpo e o direito reprodutivo, indica-nos que vivenciamos, no Brasil colonial e no Brasil imperial, uma escravidão tanto sexual quanto semi-industrial, cujo desenvolvimento foi a "semente das relações de classe e de gênero no Brasil". Ainda sobre o assunto, o autor falanos que, "do ponto de vista do patriarca, existe, também, uma série de motivos racionais para aumentar, na maior medida possivel, seu raio de influência por meio da família poligâmica" (SOUZA, 2017, p. 54), assim como para manter as tiranias privadas da esfera sexual. Ou seja, o domínio sobre a mulher traria mais controle aos homens (aos brancos, principalmente) ao atribuir aos filhos - na maioria das vezes, oriundos de estupros - funções de confiança, militares etc., a fim de defender os seus interesses.

Historicamente, portanto, como nos apresenta Teles (1993), as mulheres, desde a colônia, são a parcela da população mais explorada, pois, além das tarefas diárias do lar e do trabalho (tecelagem, fiação, pomar etc.), eram exploradas (de modo fisico e sexual), tendo os seus corpos controlados por um outro, um contexto no qual a mulher negra e escravizada era, também, um "instrumento de prazer sexual do seu senhor, podendo até ser alugada a outros senhores" (TELES, 1993, p. 21). E, como estratégia de resistência, muitas mulheres negras, que se recusavam a manter o status de sua escravidão, praticavam o aborto ou matavam o seu filho recém-nascido.

Partimos, em primeiro, da compreensão segundo a qual devemos analisar os corpos em suas corporeidades ideológicas e signicas, enquanto representações discursivas no interior das quais se entrecruzam, conflituosamente, distintos índices de valor. E, em segundo, podemos entendê-los somente enquanto manifestações corpóreas formando-se nos e pelos seus posicionamentos ideológicos na sua alteridade constitutiva e reguladora, que os 
marca desde o seu principio na história, nas quais se constituem como encarnações ideológicas enquanto corpos significados e valorados.

A partir de nosso entendimento, portanto, sobre os fenômenos discursivos sobre os corpos em suas representações ideológicas e signicas - vistos, aqui, em sua especificidade conceitual -, vamos nos direcionar a uma polêmica cuja ocorrência se iniciou no final de maio de 2019 . na qual o político Fernando Holiday, vereador pela cidade de São Paulo (SP), anunciou, de sua autoria, um Projeto de Lei (PL) através do qual se permitiria, se aprovado, o estabelecimento de complicações e de proibições à realização do aborto, mesmo tratando-se de casos nos quais o engendramento do feto pudesse se dar por meio da violência do ato de estupro.

Logo, utilizando-nos, precipuamente, no âmbito de uma Análise Dialógica do Discurso, das reflexões de Mikhail Bakhtin (2010, 2011 2017, 2019) e de Michael Foucault (1999, 2002), objetivamos analisar os aspectos discursivos e ideológicos do PL, cuja ocorrência revelase como um ato simbólico de coisificação, de controle e de dominio, que se irradiam a partir das relações de poder de nossa sociedade machista e patriarcal, dos e sobre os corpos femininos através dos processos de sua representação pela palavra em ausência, ato por meio do qual se nega, às mulheres, o direito e a autonomia da produção de seu verbo sobre si mesmas, isto é, de seu ato enunciativo de si para e sobre si no processo de suas representações em uma arquitetônica específica.

\section{Princípios metodológicos}

As nossas análises ancoram-se sobre, em primeiro, os pressupostos do correlacionamento (BAKHTIN, 2011, p. 400-401), pelo qual estabelecemos associações conceituais para uma mais profunda compreensão responsiva dos processos sobre os quais nos debruçamos. Para fazê-lo, relacionamos certos enunciados bakhtinianos em um diálogo com determinadas enunciações foucaultianas, uma vez que, segundo Bakhtin (2011, p. 400), "cada palavra (cada signo) do texto leva para além dos seus limites. Toda interpretação é o correlacionamento de dado texto com outros textos". Logo, para desenvolvermos os nossos entendimentos ativos sobre o material de nosso corpus, realizamos um intercâmbio dialético entre vozes históricas e sociais. "Salientemos que esse contato é um contado dialógico entre textos (enunciados) e não um contato mecânico de 'oposição'" (BAKHTIN, 2011, p. 401).

Em segundo, fundamo-nos na não omissão do nome do autor do Projeto de Lei, haja vista que o compreendemos como a materialização de uma representação de um sujeito social, cujos lugares ideológicos, na sociedade, formam-se como insubstituiveis a partir de seus posicionamentos ideológicos, que se referem ao conhecimento geral devido às suas funções políticas no serviço público, já que se trata, portanto, de um agente do Estado. O que analisamos, então, refere-se ao domínio estatal, mas materializa-se a partir de um sujeito único, ato pelo qual se responsabiliza. Trata-se de um expediente, cujas propostas se direcionam, com as suas consequências e as suas problemáticas, a classes e a grupos de nossa sociedade.

\section{Apontamentos epistemológicos}

Recentemente, deparamo-nos com Apontamentos dos anos de 1940, de Bakhtin (2019), obra na qual o filósofo russo colocase contra um determinado conceito de representação, seja do objeto, seja do sujeito, a partir do qual se desconsideram, no primeiro caso, as unicidades objetais ${ }^{3}$ e, no segundo caso, as unicidades arquitetônicas, ${ }^{4}$ em suas

\footnotetext{
3 Refere-se às caracteristicas únicas de sentido de cada objeto, quando representados pelos sujeitos nos acontecimentos uniocorrentes nos quais se instauram em alteridade. A sua unicidade advém-se de sua inesgotabilidade e de sua irrepetibilidade no transcurso da eventicidade histórica, uma vez que são representações discursivas - portanto, ideológicas.

4 Não nos deteremos, agora, nos desdobramentos epistemológicos do conceito de arquitetônica de Bakhtin (2010). Fazemo-lo, contudo, a seguir. O que necessitamos de observar é: cada sujeito define-se como uma arquitetônica, no sentido de que se trata de uma articulação dinâmica e processual - sempre aberta e inacabada, como um devir - de representações discursivas - portanto, ideológicas - que se formam nas e pelas relações dialógicas entre as suas três instâncias: o eu-para-mim, o outro-para-mim e o eu-para-o-outro, o que veremos de modo mais detalhado. As relações entre os sujeitos tratam-se de interações entre arquitetônicas. Porém, compreendamos que cada arquitetônica se caracteriza por ser, dialeticamente, alteritária e única, de onde se forma a ideia de unicidade arquitetônica.
} 
localizações culturais, históricas e sociais, que se tornam consideráveis e possiveis somente se admitirmos a imprescindibilidade da abertura, do inacabamento e da inesgotabilidade dos objetos e dos sujeitos nos enunciados pelos quais se constituem a sua representação provisória. Em ambas as ocorrências, quando desconsideramos a provisoriedade e a relatividade do acabamento de nossas representações, que se ancora na impossibilidade de estabelecermos uma determinação absoluta - o em si, o que esgotaria o objeto e o sujeito - sobre o que é o objeto e o que é o sujeito para além de nossa localização cultural, histórica e social, há a ocorrência da coisificação através de uma atitude monológica manifesta na ordem composicional dos nossos enunciados, pelos quais se efetivam as nossas representações dos objetos e dos sujeitos, tratando-se, nas palavras do filósofo russo, de uma palavra em ausência, isto é, de "[...] um golpe de fora [...]" (2019, p. 45).

Em breves palavras, podemos definir 0 monologismo como uma atitude por meio da qual há a escamoteação das presenças enunciativas do outro - das suas vozes - na composição de um enunciado. Pela monologização, escutamos, nos discursos, apenas certas palavras, às quais se associa uma voz coisificadora ${ }^{5}$ - cuja presença autoritária e una realiza-se pelo silenciamento das outras. Em correlação à atitude monológica, identificamos o gnosiologismo, que se refere ao processo de envolvimento das consciências - às quais se correspondem as vozes escamoteadas - por uma. Trata-se de uma consciência, segundo Bakhtin (2011, p. 81), cuja "unidade é unidade dela, ela não pode admitir ao seu lado outra unidade independente dela [...], uma unidade soberana que lhe faça frente com seu próprio destino não determinado por ela". Entretanto, não há ato de linguagem, como entendemos, que possa se realizar por meio da presença de uma voz una, mas há posicionamentos ideológicos de sujeitos que buscam silenciar outras vozes que não sejam a(s) sua(s).

Entretanto, a problemática se torna, segundo a nossa compreensão, mais grave e profunda quando nos voltamos aos processos de representação pelos quais se sufoca a unicidade arquitetônica do sujeito, já que se constitui uma desconsideração da sua abertura e do seu inacabamento, em correlação com o silenciamento de seus atos enunciativos sobre si. Trata-se de um gnosiologismo - cujas origens, segundo Bakhtin (2011, p. 80), situam-se na "...] cultura filosófica dos séculos XIX e XX" -, através do qual se instaura a rejeição da unicidade arquitetônica do sujeito, aliandose a um monologismo. Trata-se de uma ação, de situacionalidade histórica e de constituição ideológica, à qual, junto a Bakhtin (2011), podemos chamar de atitude de uma consciência gnosiológica, que "cria e forma seu objeto somente enquanto objeto e não enquanto sujeito, e o sujeito não passa de objeto para ela" (2011, p. 81).

Bakhtin (2017), em Fragmentos de 1970-1971, apresenta-nos a existência de três formas de relações, que configuram, para nós, como chaves interpretativas necessárias ao esclarecimento de parte das problemáticas às quais nos voltamos aqui. Segundo o filósofo russo, podemos determinar a existência de relações: 1) entre objetos, "entre coisas, entre fenômenos físicos, fenômenos químicos; relações causais, relações matemáticas, lógicas, relações linguisticas, etc." (2017, p. 30); 2) entre sujeito e objeto; e 3) entre sujeitos, que são, segundo as suas palavras,

as relações pessoais, as relações personalistas:
relações dialógicas entre enunciados, relações
éticas, etc. Ai se situam quaisquer vínculos
semânticos personificados. As relações entre
consciências, verdades, influências mútuas,
a aprendizagem, o amor, o ódio, a mentira, a
amizade, o respeito, a reverência, a confiança,
a desconfiança, etc. (2017, p. 30 ).

No entanto, necessitamos nos ater a dois processos pelos quais as formas de relações supracitadas sofrem, em sua constituição, modificações substanciais a partir das condições históricas e sociais de sua realização, aos quais Bakhtin se refere como coisificação e personificação, correlatos opostos. O primeiro 
trata-se de um processo de despersonificação, pelo qual se retira a possibilidade de realização autônoma do ativismo responsivo do sujeito, o que se dá pelo movimento de aniquilação ou de sufocamento da sua unicidade arquitetônica através da busca constante da eliminação ou do silenciamento dos atos enunciativos do sujeito sobre si. Sobre isso, Bakhtin (2017, p. 30-31) diz-nos que, "por outro lado, é possivel a personificação de muitas relações objetificadas e a sua passagem para o terceiro tipo". A personificação, portanto, realiza-se como o ato de consideração da unicidade e da uniocorrência do objeto ou do sujeito, uma vez que precisamos de considerar "[...] concretude (nome), integridade, responsividade, etc., inesgotabilidade, inconclusibilidade, abertura" (2017, p. 31, grifo nosso).

Lembremo-nos de que só nos é possivel que nos relacionemos com os objetos e os sujeitos através do processo de representação, que se efetiva por meio de nossos atos enunciativos. Trata-se da forma primária por meio da qual os objetos e os sujeitos se revelam à nossa consciência. Entretanto, há, aí, especificidades, às quais não nos remeteremos agora. Mas, em sintese, podemos apenas representar os objetos e os sujeitos através de nossos enunciados, significando-os e os valorando em nossas relações de alteridade, tematizando-os ao os situarmos na história e na sociedade.

Porém, gostariamos, agora, de acentuar certos detalhes do processo de coisificação, cuja constituição ocorre nos planos de duas ordens, que se refletem: no da ordem arquitetônica e no da ordem composicional. Segundo Sobral (2010, p. 69), "o dialogismo é constitutivo em termos arquitetônicos (Bakhtin 1993), mas os discursos podem ser estruturados composicionalmente de modo a apresentar ou não as marcas do dialogismo". Especificamente, a ordem arquitetônica refere-se à constitutividade estrutural dos sujeitos, condição de possibilidade para a sua existência, tratandose, portanto, da alteridade necessária para a sua constituição e para a sua existência, no espaço e no tempo. A ordem composicional, por sua vez, refere-se aos modos de construção composicional do enunciado (unidade da representação), tratando-se de dois processos específicos: um dialógico, no e pelo qual podemos evidenciar os nossos outros constitutivos e reguladores em nossos enunciados, revelando-os através de marcas discursivas e linguísticas; um monológico, no e pelo qual podemos escamotear os nossos outros por meio de recursos através dos quais almejamos silenciá-los.

Precisamos entender que os processos de representação se constituem como ideológicos, gerando-se em periodos históricos determinados. Por um de seus lados, efetiva-se e se instaura através das relações de alteridade. Segundo Bakhtin (2010, p. 114), os sentidos e os valores - ou, em outras palavras, os enunciados -, pelos quais representamos os objetos e os sujeitos - entre os quais nos enquadramos -, constituem-se e regulam-se na e pela arquitetônica, cujos momentos fundamentais são o eu-para-mim, o outro-para-mim e o eu-para-o-outro. Nas palavras do filósofo russo,

os valores da vida real e da cultura se dispõem ao redor destes pontos arquitetônicos fundamentais do mundo real do ato: valores científicos, estéticos, políticos (incluídos também os éticos e sociais) e, finalmente, religiosos. Todos os valores e as relações espaço-temporais e de conteúdo-sentido tendem a estes momentos emotivo-volitivos centrais: eu, o outro, e eu-para-o-outro (BAKHTIN, 2010, p. 115).

Na e pela arquitetônica, instauram-se os conflitos ideológicos nos processos de representação. Aqui, ressaltamos uma compreensão essencial do conceito de diálogo de Bakhtin: trata-se de conflito e de tensão entre as instâncias da arquitetônica (o eu-para-mim, o outro-para-mim e o eu-para-o-outro), manifestando-se no interior dos atos representacionais. Segundo Bakhtin (2017, p. 38, grifo nosso), "para cada indivíduo, todas as palavras se dividem nas suas próprias palavras e nas dos outros, mas as fronteiras entre elas podem confundir-se, e nessas fronteiras desenvolve-se uma tensa luta dialógica".

Por outro de seus lados, necessitamos analisar como os enunciados, unidades de nossas representações, constroem-se a partir das forças das relações de poder formadoras de nossa unicidade 
arquitetônica. Como meios pelos quais se realizam e se legitimam os discursos, os enunciados, em suas responsividades, respondem-se na composição de cadeias multidirecionais, através das quais se efetivam processos de refração de sentidos e de valores, perpetuando-se por meio de suas mudanças. Grillo e Américo (2017, p. 357) dizem-nos que qualquer enunciado "é um elo na cadeia da comunicação discursiva e um elemento indissociável das diversas esferas ideológicas (literária, científica etc.). O enunciado sempre responde a algo e orientase para uma resposta". Porém, ressaltemos que não se trata de uma formação linear, mas, sim, dialética e multidirecional.

Constituindo-se e se regulando em suas alteridades, pelos seus ativismos responsivos, ${ }^{6}$ instaurando-se em sociedades hierarquizadas e organizadas segundo as ordens discursivas, os enunciados tornam-se meios pelos quais se dão a formação, o reflexo e a refração das forças capilares e pluridimensionais das relações de poder, por intermédio das quais se constituem os sujeitos e, portanto, os discursos, tornando-se meios de instauração de forças ideológicas, cujas concretizações e legitimações se dão através das instituições, dos instrumentos, dos mecanismos e das organizações de uma sociedade. Nas palavras de Foucault (1999, p. 8-9),

[...] em toda sociedade a produção do discurso é ao mesmo tempo controlada, selecionada, organizada e redistribuída por certo número de procedimentos que tem por função conjurar seus poderes e perigos, dominar seu acontecimento aleatório, esquivar sua peada e temivel materialidade.

No interior de um enunciado, articulam-se as forças das relações de poder, por meio de uma ordem discursiva, no processo de sua constituição. Há, portanto, interdições e exclusões, que se efetivam nos processos representacionais ao não se considerar o ato enunciativo do outro sobre si, por exemplo. Foucault (1999, p. 9) oferece-nos três formas de interdição: "tabu do objeto, ritual da circunstância, direito privilegiado ou exclusivo do sujeito que fala [...], que se cruzam, se reforçam ou se compensam, formando uma grade complexa que não cessa de se modificar".

Um dos meios, portanto, pelos quais se realizam o controle e/ou a dominação dos corpos - excluindo-os e os interditando enquanto encarnações ideológicas e manifestações discursivas que se localizam em determinado periodo histórico - parece-nos ser por meio da violência do gnosiologismo e do monologismo, que se instauram na e pela palavra da imagem em ausência ${ }^{7}$ do sujeito representado. E, aqui, aproximamo-nos do vocábulo russo, explicando o nosso entendimento: na língua de Bakhtin, слово (slovo) refere-se tanto à palavra, enquanto unidade lexical, quanto ao discurso, enquanto enunciado concreto. Logo, estendemo-nos à ampliação de nossos horizontes conceituais (GRILLO; AMÉRICO, 2017, p. 364).

Sobre a palavra-violência, Bakhtin (2019, p. 43) diz-nos que

pressupõe um objeto ausente e mudo, que não escuta e não responde, não se dirige a ele, nem exige o seu consenso, é uma palavra em ausência. O conteúdo da palavra sobre o objeto nunca coincide com o seu conteúdo para si mesmo. O conteúdo lhe dá uma definição com a qual ele nunca pode concordar, por principio, interiormente. Essa palavra-violência (e mentira) conflui no criador, com milhares de motivos pessoais que turvam a sua pureza - sede de sucesso, de influência e reconhecimento (não da palavra, mas do criador), aspirando a se tornar uma força opressora e consumidora. A palavra quer exercer influência de fora e determinar de fora.

\section{E, portanto,}

na imagem não se encontram e não se unem as vozes do objeto e daquele que fala sobre ele. O objeto que saltar fora de si mesmo e vive na fé, no milagre de sua transformação repentina. A imagem o coage a coincidir consigo mesmo

\footnotetext{
6 Ato de responder a e por, tratando-se de uma resposta ao outro pelo qual o autor se responsabiliza. Como nos mostra o conceito, é uma responsividade que se funda sobre o ativismo do sujeito responsivo.

7 Trata-se da imagem em ausência do próprio sujeito representado. Podemos, de outro modo, dizer que se refere a uma representação em presença negativa do outro, negatividade que se emerge pelo silenciamento ou pelo sufocamento da sua unicidade arquitetônica no processo de construção de sua imagem. O sujeito, cuja imagem se forma em sua ausência, torna-se presente enquanto negatividade de si mesmo no enunciado pelo qual se representa, manifestando-se pela sua ausência. Vemo-lo, portanto, como uma ausência de ativismo responsivo, determinando-se pela consciência gnosiológica.
} 
e o afunda no desespero do acabado e pronto. A imagem utiliza até o final os privilégios da sua posição exotópica (BAKHTIN, 2019, p. 45).

Realiza-se na e pela desconsideração da unicidade arquitetônica e do ato enunciativo do sujeito, nas e pelas representações coisificadoras e sufocadoras do outro, cuja uniocorrência responsiva dá-se como uma forma de discurso autoritário. Segundo Bezerra (2015), o discurso autoritário define-se como

aquele vinculado a uma autoridade externa, a um poder político, a uma ideologia, ao dogma religioso ou político, a uma autoridade científica reconhecida, a uma corrente de pensamento que se pretende hegemônica, a um livro da moda; exige da nossa parte um reconhecimento incondicional, até reverente, e nunca uma assimilação livremente criadora formulada em nosso próprio discurso, com nossa marca caracteristica, e procura determinar até os fundamentos de nossa relação ideológica com o mundo e do nosso comportamento (2015, p. 244, grifo nosso).

E, no âmago das definições de Bakhtin, encontramos uma possibilidade de diálogo com Foucault (1999, p. 10), segundo o qual, "por mais que o discurso seja aparentemente bem pouca coisa, as interdições que o atingem revelam logo, rapidamente, sua ligação com o desejo e com o poder", tornando-se "[...] aquilo por que, pelo que se luta, o poder do qual nos queremos apoderar" (FOUCAULT, 1999, p. 10). No e pelo discurso, representamos o outro. E, quando nos ausentamos, pela exclusão ou pela interdição, da presença enunciativa da sua unicidade arquitetônica, a sua imagem torna-se "[...] privada de dialogicidade e de inacabamento" (BAKHTIN, 2019, p. 47): "a unidade acabada é sempre em ausência" (BAKHTIN, 2019, p. 47, grifo do autor), na desconsideração de sua inesgotabilidade. Indo além, à imagem em ausência, Bakhtin associa a mentira - "forma contemporânea mais atual do mal" (2019, p. 49). Segundo as suas próprias palavras, "a mentira nas formas da seriedade (unidas ao medo, à ameaça, à violência). Ainda não há as formas da força (autoridade, poder) sem o ingrediente necessário da mentira" (BAKHTIN, 2019, p. 49, grifo nosso).
Levando em consideração a compreensão de que os corpos se manifestam enquanto discursos por meio de suas corporeidades, buscamos analisar o estabelecimento de sua constituição, como representação, a partir do Projeto de Lei perpetrado pelo vereador Fernando Holiday, analisando como, enquanto discursos do e sobre o corpo, dão-se as representações dos sujeitos em suas unicidades históricas e sociais.

\section{Análises responsivas}

Como falamos nos tópicos anteriores, no dia 29 de maio de 2019, protocolou-se, na Câmara Municipal de São Paulo, o Projeto de Lei (PL) n. 01-00352/2019, de autoria do vereador Fernando Holiday. Aqui, vamos nos delimitar, entretanto, a partes especificas do referido PL, como atitude metodológica necessária à concisão de nosso espaço.

O que, em primeiro, gostaríamos de destacar volta-se a uma das características linguísticas de qualquer Projeto de Lei: a sua forma imperativa, por meio da qual se determina a sua feição categórica e normativa, formando-se, em sua discursividade, a partir de um ato monológico através do qual se desconsideram, de antemão, as possiveis réplicas dialógicas dos outros, aos quais se busca negar posicionamento ideológico em relação ao conteúdo imposto ou instituido. Mais adiante, veremos o caráter normativo do PL pela sua composicionalidade imperativa, o que nos revela, concomitantemente, o desdobramento de uma atitude gnosiológica de um ato monológico da ordem arquitetônica à composicional.

Leiamos o seguinte artigo:

Art. $2^{\circ}$ - O Município só realizará o procedimento do abortamento de feto ou embrião mediante a apresentação de alvará expedido por autoridade judiciária.

$\$ 1^{\circ}$ - Os alvarás judiciais serão submetidos à Procuradoria-Geral do Municipio que, se entender que é o caso, oferecerá recurso ou entrará com a medida cabivel para suspendê-los e cassá-los.

$\$ 2^{\circ}$ - O abortamento não será realizado na pendência de julgamento de tais medidas (SÃO PAULO, 2019, p. 1).

Pelo PL, de acordo com o seu texto original, 
enquanto um ato enunciativo de normatização, visa-se à criação de "medidas de apoio à mulher gestante e à preservação da vida na rede municipal de saúde" (SÃO PAULO, 2019, p. 1). Para tanto, propõe-se, em seu artigo primeiro, que, desde o momento da concepção, deve-se considerar a vida do nascituro. Institui-se, ainda, que para a realização do aborto - nos casos já legalizados por lei - só se poderá realizá-lo mediante um alvará expedido por autoridade judiciária, o que podemos relacionar ao que Foucault (1999) conceitua como um "[...] discurso pronunciado por quem de direito e conforme o ritual requerido" (FOUCAULT, 1999, p. 15).

Sobre ambos os dois primeiros pontos, podemos pensar que o momento da concepção como premissa para o início da vida deixa-nos claro a predominância discursiva religiosa em uma sociedade laica. Ora, uma mulher agnóstica ou ateia - respaldando-se pela ciência - pode não ter a concepção como o ponto de início da vida. Sobre o alvará, aparece-nos o princípio do processo de coisificação: passa-se a entender o sujeito como objeto passivel de obter uma permissão para a realização de um procedimento em seu próprio corpo. Submete-se a mulher aos regulamentos de um estado patriarcal, silenciando-se pelos atos normativos de documento, comparando-se a um negócio para o qual se necessita da obtenção de um alvará. Em outras palavras, torna-se vítima de uma atitude gnosiológica.

Já no artigo terceiro, encontramos a proposição segundo a qual a gestante, em posse do alvará, deverá - e, aqui, não nos esqueçamos do uso do imperativo - aguardar mais quinze dias para a realização do aborto, prazo no qual precisará de se submeter, obrigatoriamente, a "atendimento psicológico com vistas a dissuadi-la da ideia de realizar o abortamento" (SÃO PAULO, 2019, p. 1). Deparamo-nos com uma posição antiética em relação à categoria dos psicólogos, pois, segundo o Código de Ética Profissional do Psicólogo (2005), a dissuasão de um paciente se trata, discursivamente, de uma forma de imposição - monológica, diriamos - de um discurso e de um valor a outrem. No artigo segundo do referido código de ética, veda- se ao psicólogo a indução da ou do paciente a "convicções políticas, filosóficas, morais, ideológicas, religiosas, de orientação sexual ou a qualquer tipo de preconceito" (BRASIL, 2005, p. 9).

No excerto acima, emerge-se, sob a nossa perspectiva, a constituição da ordem juridica, que se funda, como nos aponta Foucault (2002), genealogicamente, na percepção de que se emerge a partir de processos de origem, o que nos permite compreender a constituição das formas juridicas por meio da consagração dos princípios e das regras como verdades originárias a partir das quais se formam as forças legitimadoras, por exemplo, de saberes como os do Direito. Daí, criam-se as estruturas históricas pelas quais se determinam as legitimidades de certos discursos, assim como o seu pertencimento às esferas de aceitação. E, no caso do PL, o ato enunciativo funda-se no entrecruzamento discursivo com a esfera jurídica, na desconsideração dos processos dialógicos de atitude empática, uma das únicas através das quais se pode evitar o gnosiologismo nos processos de constituições dos e das relações entre os sujeitos, que se reflete como um monologismo na ordem composicional. Forma-se a imagem em ausência da mulher, evidenciando-se a violência do controle ideológico sobre os seus direitos.

Em adição, institui-se, no terceiro parágrafo do Art. $3^{\circ}$ do PL, uma prescrição cuja obrigatoriedade se constitui como um ato de violência jurídica, psicológica e simbólica contra a mulher, que necessitará de se submeter a "exame de imagem e som que demonstre a existência de órgãos vitais, funções vitais e batimentos cardiacos" (SÃO PAULO, 2019, p. 1), como se fossem os parâmetros incontestáveis e universais para estabelecimento da vida, justificando-se com o argumento de que se geraria, assim, algum tipo de "empatia" na gestante em relação ao feto, para que desista do processo de abortamento. No entanto, na prática, seria mais uma etapa de violência contra a mulher, corrosão dos seus direitos sobre os seus corpos, física e simbolicamente.

Pelo artigo quinto do PL, determina-se que, "obrigatoriamente, a gestante passará por atendimento religioso, sempre que ela e seus 
pais expressarem qualquer forma de teísmo" (SÃO PAULO, 2019, p. 1). Notamos, novamente, a presença constitutiva do discurso religioso, enquanto discurso alheio se tornando discurso autoral (VOLÓCHINOV, 2017, p. 249) - o que se trata do posicionamento ideológico a partir do qual o sujeito do ato enunciativo se constitui -, imiscuindo-se no enunciado do vereador, reiterando-se, pela sua formação enquanto um discurso autoritário, a desconsideração da unicidade arquitetônica das mulheres, como apontamos a partir de Bezerra (2015). Trata-se de um processo cuja ocorrência enquadra-se nas considerações de Bakhtin (2017) sobre a palavra: "[...] palavra sagrada do outro e, em geral, da palavra sagrada e autoritária com sua indubitabilidade. incondicionalidade, irrestritividade" (2017, p. 22), que "[...] inibe e bloqueia o pensamento. A palavra que exige repetição reverente e não um desenvolvimento sucessivo, correções e complementos" (BAKHTIN, 2017, p. 22). Isto é, há a presença, no projeto proposto, das forças religiosas como discursos constitutivos.

Ainda, para percebermos os entrecruzamentos discursivos entre diferentes esferas ideológicas no interior do enunciado o qual analisamos, observemos o seguinte artigo:

Art. $6^{\circ}$ - Se, em qualquer caso de atendimento médico, for detectada uma gravidez em que as condições sociais e psicológicas da gestante indiquem propensão ao abortamento ilegal, o Municipio requererá medidas judiciais cabiveis para impedir tal ato, inclusive a internação psiquiátrica, nos termos da Lei federal 10.216 de 2001 (SÃO PAULO, 2019, p. 2).

O que chama a nossa atenção na citação acima são certos discursos pelos quais conseguimos mapear a genealogia da constituição de duas forças centrípetas ${ }^{8}$ no PL do referido vereador: a jurídica, a religiosa, a médica - às quais nos referimos brevemente - e, agora, a psiquiátrica. Trata-se de formas discursivas e ideológicas através das quais se realizam os procedimentos de categorização exclusiva ou inclusiva de outras manifestações do discurso. Por um lado, percebemos que se evidenciam certas ideias propostas e discutidas por Foucault (1999, p. 9) sobre o "[...] direito privilegiado ou exclusivo do sujeito que fala", uma vez que se remetem a discursos considerados, em nossa sociedade, como pertencentes a autoridades legitimadas em correlação com as suas respectivas esferas ideológicas. Portanto, como nos apontam Ponzio, Calefato e Petrilli (2007, p. 240),

[...] essas relações se acham intimamente ligadas a uma ordem do discurso fundado sobre regras ao mesmo tempo proibitivas e gerativas que, por um lado, reduzem e segregam o corpo na sua 'autonomia' e, pelo outro, o transformam em fonte primária do discurso social que tem como referente seu o 'sexo' na sua pretensa naturalidade.

Aqui, a "[...] própria noção de 'corpo' é ao mesmo tempo um produto do discurso e princípio gerador do discurso [...]" (PONZIO; CALEFATO; PETRILLI, 2007, p. 241). Logo, criam-se as possibilidades de formação de certas representações sobre os corpos femininos cujas significações ideológicas se tornam constitutivas de um imaginário social ou, como preferimos, de uma memória societal, no e pelo movimento responsivo das enunciações no transcurso do tempo histórico, o que nos mostra, por outro de seus lados, como as regulações ideológicas exercem-se no movimento dialético entre a exterioridade e a interioridade dos discursos e das representações.

De outra forma, podemos entender como os corpos, enquanto significações ideológicas - isto é, produções discursivas -, controlam-se a partir do seu interior, uma vez que as forças coercitivas e definidoras das relações de poder se tornam constitutivas do modo como o sujeito constrói-se e representa-se para si mesmo, processo a partir do qual as forças ideológicas se formam e se manifestam, refratando-se e variando-se segundo as condições materiais da existência das classes e/ ou dos grupos, não somente em um eixo vertical,

\footnotetext{
8 Forças pelas quais se realiza o movimento de conservação e de perpetuação de um estado de coisas. A centripetação volta-se para um ponto localizado no âmago, formando-se, logo, uma centralização. Aqui, por exemplo, compreendemos o machismo como uma das forças centripetas pelas quais o estado patriarcal conserva-se e se perpetua. O seu contrário institui-se pela centrifugação, movimento pelo qual se dá a descentralização. Um exemplo parece-nos ser o dos movimentos sociais através dos quais se buscam direitos, deveres e liberdades contra uma e em relação a uma organização na qual se privilegia a dominação e a desigualdade.
} 
mas, também, em um horizontal, entre sujeitos assimétricos em constante relação dialógica.

Sabemos, pelos estudos de Foucault (1978, 1999), que o discurso psiquiátrico se funda no estabelecimento da normalidade, ao lado do qual se colocam os enunciados produzidos nas esferas ideológicas da Medicina e da Psiquiatria, em oposição à anormalidade, ao lado do qual se colocam, pelas forças centripetas dos discursos psiquiátricos e médicos, os sujeitos, com os seus enunciados, que não se enquadram nos padrões determinados por ambas as esferas, o que se configura como um meio pelo qual se localizam e se situam os sujeitos loucos, delimitandoos a um espaço fora do âmbito dos discursos legitimados e legitimadores das ciências médicas e psiquiátricas. Os loucos, cuja palavra "[...] não era ouvida, ou então, se era ouvida, era escutada como uma palavra de verdade" (FOUCAULT, 1999, p. 11), logo, colocavam-se à margem, o seu espaço circunscrito pelas relações de poder.

Os riscos encontram-se na impossibilidade de formação de critérios de objetividade absoluta para a determinação dos padrões de normalidade, o que se constitui como uma brecha para o estabelecimento de atuações ideológicas e subjetivistas por parte do profissional que dará o diagnóstico pelo qual se determinará se a gestante possui "propensão" à realização ilegal do abordo, excluindo as possibilidades enunciativas da mulher sobre si ao atuar de forma coercitiva em relação ao discurso, ao sujeito e ao corpo da mulher. Como consequência punitiva, determina-se, para a gestante diagnosticada, o controle de seu corpo, haja vista que se representará a mulher, para o e pelo estado, como um sujeito perigoso cuja corporeidade classifica-se como inadequada, segundo os critérios estipulados pelo PL. À mulher, prescreve-se que deve ocupar o espaço discursivo da loucura, pelo qual se determina a sua insanidade e a sua incapacidade, mesmo quando se trata do exercício do seu direito sobre si.

De outro modo, podemos apontar como o gnosiologismo trata-se de um duplo movimento dialético: manifesta-se como a causa de um processo ou de um procedimento, revelando- se, porém, em seu próprio efeito. Isto é, realizase na separação e na rejeição (FOUCAULT, 1999, p. 10) do ato monológico, quando se dá a aproximação entre a mulher "propensa ao aborto" e a figura submissa do louco, procedimentos cuja materialidade é a aparição do fenômeno gnosiológico. Quando, pelo PL, determina-se a internação psiquiátrica da mulher, cria-se uma zona limitrofe entre a anormalidade e a normalidade, na qual se efetivam a separação e a rejeição da palavra da mulher sobre si: a sua voz emudece-se ao cair no nada, "rejeitada tão logo proferida" (FOUCAULT, 1999, p. 11). E, portanto, devemos concordar com Foucault (1999, p. 13), segundo o qual a separação, "longe de estar apagada, se exerce de outro modo, segundo linhas distintas, por meio de novas instituições e com efeitos que não são mais os mesmos".

Pela atitude gnosiológica, o PL configura-se como um enunciado monológico, dando-nos condições para avaliarmos uma forma especifica de alteridade no processo de representação: um modo à parte do ativismo responsivo de um sujeito pela violência da palavra em ausência.

\section{Considerações finais}

A partir de nossas análises e de nossas discussões, pudemos compreender parte do processo de coisificação e de sufocamento exercido sobre os corpos e as corporeidades das mulheres. O PL proposto trata-se de um enunciado, que se configura como um posicionamento ideológico cuja uniocorrência se afirma como uma violência contra os sujeitos representados: as mulheres, cada qual em sua unicidade, mas, principalmente, como um corpo uno de constituição alteritária e, portanto, coletiva.

Percebemos, principalmente, a presença, no composicional, de uma postura monológica, que se decorre, de maneira análoga ao que nos aponta Bakhtin (2011) em O autor e o personagem na atividade estética, de uma atitude gnosiológica, cuja prática se refere não apenas à exclusão das vozes femininas - sobre si, os seus corpos e as suas corporeidades - do enunciado proposto, mas, sim, da realização da palavra em ausência, 
ato através do qual se realizam os processos de representação das mulheres como coisas, na busca pela eliminação das possibilidades de realização de suas corporeidades enquanto enunciados.

Para o corpo feminino, compreendido como coisa ou como objeto, utilizando-nos de uma ressignificação da palavra de Bakhtin (2019, p. 42), "[...] é prescrito para ele de fora quem ele deve ser, privam-no dos direitos de uma autodefinição livre, definem-no e o bloqueiam por meio dessa autodefinição". Trata-se do movimento centrípeto das forças do machismo para a conservação e a perpetuação do estado patriarcal, cuja constituição e cuja estrutura equivalem-se às potências das posições superiores nas hierarquias sociais e nas relações de poder, como afirmáramos.

No enunciado do vereador Holiday, manifestamse, explicita e/ou implicitamente, outros atos enunciativos pelos quais o patriarcado se funda e se sustenta, formando-se, portanto, uma série, responsivamente, das cadeias multidirecionais de enunciados pelas quais se perpetua, pela sua mudança, o machismo estrutural e o sistêmico da sociedade brasileira.

Compreendemos que o monologismo se refere não apenas a uma forma de construção e de organização da composição do enunciado, mas, sim, a um reflexo refratado de uma atitude ética e existencial em relação ao outro, o que se trata de uma especificidade da constituição do sujeito em sua ordem arquitetônica, cujo ato escamoteador das vozes alheias se trata da manifestação da volição do seu ativismo responsivo, pela qual deseja, objetificando-o ao despersonificá-lo, coisificar e/ou silenciar o seu outro constitutivo e regulador - mesmo que seja o seu oposto.

Portanto, ao contrário do que se pensa, a constituição monológica, manifestada na ordem composicional, mostra-se como um posicionamento ideológico de uma atitude gnosiológica, pela qual se busca a perpetração do processo de coisificação do outro, dando-nos a possibilidade para compreendermos a ocorrência do ato de determinação ontossemântica - isto é, da prescrição do que se deve ser -, que se revela a partir de uma enunciação monológica, por exemplo. Segundo Bakhtin (2019), pelo processo de determinação objetal e de prescrição ontossemântica, priva-se o sujeito de sua "liberdade, o ato de conhecimento quer circundálo de todas as partes, quer isolá-lo de sua incompletude, portanto da liberdade, do futuro provisório e semântico, de sua irresolução e da verdade interior" (2019, p. 41-42). Eis-nos, aí, diante de um meio pelo qual se gera a mortificação dos corpos femininos através de sentidos ideológicos.

Às mulheres, sobre os seus corpos e as suas corporeidades, em relação ao exercício dos seus direitos, nega-se a palavra sobre si, despersonificando-as. Cria-se um abismo assimétrico entre as instâncias da relação sobre a qual nos debruçamos: o eu - que se representa pelo vereador Holiday, através do qual se manifestam as forças do machismo e do patriarcado - e o outro - que se representa pela coletividade feminina. O eu, então, sobrepõese ao outro. Ao outro - isto é, às mulheres -, no PL, busca-se negar a possibilidade de personificação, isto é, do processo pelo qual poderiam, para si e para outrem, manifestar-se como sujeitos ativos e responsivos em suas unicidades arquitetônicas, pelas suas próprias palavras. Há apenas o eu se enunciando sobre o outro, cujo ativismo responsivo se sufoca pela atividade das potências das relações de poder articulando-se no entrecruzamento de discursos legitimadores de distintas esferas ideológicas, o que se manifesta como um gnosiologismo pela monologização discursiva. O enunciado do eu, aqui, trata-se de uma palavra-violência.

Efetiva-se, entendemos, o processo de sufocamento da "interna infinitude valorativa [...]" (BAKHTIN, 2019, p. 46) da mulher de si para e sobre si, pelo qual se faz, através das forças ideológicas do machismo e do patriarcado, apropriando-nos das palavras de Bakhtin (2019, p. 46), o "[...] fechamento da sua imagem exterior em ausência no outro". A negação da liberdade inerente do sujeito, que se realiza enquanto um eu-para-mim (ou um eupara-si) em seu ativismo responsivo, trata-se da manifestação das relações de poder, pelas quais, logo, podemos entender como os corpos femininos 
revelam-se como encarnações ideológicas e representações signicas, aparições discursivas cuja constituição insere-se na cadeia dos enunciados e, consequentemente, na ordem dos discursos

E, enquanto discursos, são, desde o seu intrinseco, controlados, selecionados, organizados e redistribuidos, como nos evidencia Foucault (1999, p. 9). As manifestações corporais das mulheres, através de seus posicionamentos ideológicos, isto é, de suas corporeidades, sofrem, portanto, os processos de exclusão, o que se dá, por um lado, pela constituição da problemática do aborto em nossa sociedade machista, cujo centro de forças desenvolve-se a partir de uma fonte patriarcal, escravocrata e burguesa, em uma tradição judaico-cristã. Aí, revelam-se os olhares ideológicos sobre o aborto, uma vez que se configura como tabu do objeto (FOUCAULT, 1999, p. 9), refletindo-se nos corpos femininos enquanto discursos em processo.

Conseguimos ver, logo, que há o conflito entre vozes sociais, pelo qual se efetiva uma sobreposição assimétrica e violenta de uma em relação a(s) outra(s). Longe de constituirse como um fenômeno unilateral, de solução consensual, o PL se mostra como um sintoma em uma série de aparições fenomenológicas, dando-se como um posicionamento ideológico cujo acontecimento, na realidade da vida, ligase a outros no movimento dialético do espaço social e do tempo histórico.

Vale-nos considerar a sua pertinência para percebermos o machismo estrutural e sistêmico que busca coisificar, silenciar e sufocar as mulheres, com os seus corpos e as suas corporeidades, ao representá-las pela palavra enquanto uma unidade coisificadora e determinante, em ausência da unicidade arquitetônica das vozes femininas. E, dentre as estratégias e os mecanismos de perpetuação de uma ordem do discurso, destacam-se o gnosiologismo - da ordem da constituição dos sujeitos - e o monologismo - da ordem da composição dos enunciados -, manifestandose como processos de objetificação de outrem.

\section{Referências}

BAKHTIN, M. Fragmentos dos anos 1970-1971. In: BAKHTIN, M. Notas sobre literatura, cultura e ciências humanas. Organização, tradução, posfácio e notas de Paulo Bezerra. São Paulo/SP: 34, 2017, p. 21-56.

BAKHTIN, M. O autor e a personagem na atividade estética. In: BAKHTIN, M. Estética da criação verbal. Tradução de Paulo Bezerra. 6. ed. São Paulo/SP: WMF Martins Fontes, 2011, p. 3-186.

BAKHTIN, M. O homem ao espelho: apontamentos de 1940. São Carlos/SP: Pedro e João Editores, 2019.

BAKHTIN, M. Para uma filosofia do ato responsável. Tradução de Valdemir Miotello e Carlos Alberto Faraco. São Carlos/SP: Pedro \& João Editores, 2010.

BRASIL. CONSELHO FEDERAL DE PSICOLOGIA. Código de ética profissional do Psicólogo. 2005. Disponivel em: https://site.cfp.org.br/documentos/ confira-o-novo-codigo-de-etica-profissional-do-psicologo/. Acesso em: 14 ago. 2019.

FOUCAULT, M. A ordem do discurso. 5. ed. São Paulo/SP: Edições Loyola, 1999.

FOUCAULT, M. A verdade e as formas juridicas. 3. ed. Rio de Janeiro/RJ: NAU Editora, 2002.

FOUCAULT, M. História da loucura. São Paulo/SP: Editora Perspectiva, 1978.

FOUCAULT, M. História da sexualidade: a vontade de saber. Rio de Janeiro/RJ: Edições Graal, 1988.

GRILLO, S.; AMÉRICO, E. Glossário. In: VOLÓCHINOV, V. Marxismo e filosofia da linguagem: problemas fundamentais do método sociológico na ciência da linguagem. Tradução, notas e glossário de Sheila Grillo e Ekaterina Vólkova Américo. São Paulo/SP: 34, 2017. p. 353-367.

MUNICÍPIO DE SÃO PAULO. CÂMARA MUNICIPAL. Projeto de Lei 01-00352/2019. Cria medidas de apoio à mulher gestante e à preservação da vida na rede municipal de saúde. Disponivel em: http://documentacao.saopaulo.sp.leg.br/iah/fulltext/projeto/ PL0352-2019.pdf. Acesso em: 16 ago. 2019.

PONZIO, A.; CALEFATO, P.; PETRILLI, S. Fundamentos de filosofia da linguagem. Tradução de Ephraim Ferreira Alves. Petrópolis: Vozes, 2007.

SOBRAL, A. A estética em Bakhtin (literatura, poética e estética). In: DE PAULA, L.; STAFUZZA, G. (org.). Circulo de Bakhtin: teoria inclassificável. Série Bakhtin: Inclassificável, v. 1. Campinas/SP: Mercado de Letras, 2010, p. 53-88.

SOUZA, J. A elite do atraso: da escravidão à Lava Jato. Rio de Janeiro: Leya, 2017.

TELES, M. Breve história do feminismo no Brasil. São Paulo: Brasiliense. 1993. 
VOLÓCHINOV, V. Marxismo e filosofia da linguagem: problemas fundamentais do método sociológico na ciência da linguagem. Tradução, notas e glossário de Sheila Grillo e Ekaterina Vólkova Américo. São Paulo/SP: 34, 2017

VOLÓCHINOV, V. A palavra na vida e a palavra na poesia: ensaios, artigos, resenhas e poemas. Organização, tradução, ensaio introdutório e notas de Sheila Grillo e Ekaterina Vólkova Américo. São Paulo/SP: 34, 2019.

\section{Fábio Luiz de Castro Dias}

Graduando em Letras pela Universidade Federal de Lavras (UFLA, Lavras, MG, Brasil).

\section{Marina Alvarenga Botelho}

Mestre em Educação pela Universidade Federal de Lavras (UFLA, Lavras, MG, Brasil), professora da Universidade Federal de São João Del-Rei (UFSJ) em São João Del-Rei, MG, Brasil.

\section{Marco Antonio Villarta-Neder}

Doutor em Linguística e Língua Portuguesa pela Universidade Estadual Paulista Júlio de Mesquita Filho (UNESP, Araraquara, SP, Brasil), professor da Universidade Federal de Lavras (UFLA) em Lavras, MG, Brasil.

\section{Endereço para correspondência}

Fábio Luiz de Castro Dias

Avenida Edson Haddad, 447

Monte Libano, 37202-596

Lavras, MG, Brasil

Marina Alvarenga Botelho

Universidade Federal de São João Del-Rei, Campus Tancredo Neves

Departamento de Comunicação Social

Rua Marechal Bittencourt, 24

Centro, 36300-070

São João Del-Rei, MG, Brasil

Marco Antonio Villarta-Neder

Universidade Federal de Lavras, Campus Sede

Departamento de Estudos da Linguagem

Caixa Postal 3037, 37200-900

Lavras, MG, Brasil 